\title{
Métodos quantitativos de apoio à bibliometria: a pesquisa operacional pode ser uma alternativa?
}

\author{
Paulo C ésar R odrigues B orges \\ Engenheiro cartógrafo e mestre em Sistemas e C omputação pelo Ins- \\ tituto Militar de Engenharia (RJ); professor universitário; doutoran- \\ do do curso de C iência da Informação do D epartamento de Ciência \\ da Informação e D ocumentação da U nB. \\ http://pcrb.tripod.com.br
}

\section{Resumo \\ O objetivo deste trabalho é apresentar uma forma alternativa para aplicar os métodos da Pesquisa Operacional aos fenômenos bibliométricos que surgiram no início do século $X X$, até hoje muito polêmicos. Dentre as várias formulações no campo da bibliometria, a chamada "lei de Bradford" foi o foco da investigação. Tentativas deste gênero podem ser uma saída para sistematizar conceitos na bibliometria, confirmando ou descartando descrições e princípios oriundos de suas formulações empíricas. Tendo por base uma linha de analogia entre fenômenos físicos da Teoria do Caos - resolvidos pela Pesquisa Operacional (PO) - e casos de oferta e procura de periódicos, é possível encontrar uma explicação para o comportamento anômalo da curva de Bradford em certas condições críticas. Para aduzir alguma evidência empírica para este ensaio, dois casos práticos na área da $P O$ foram adaptados para a resolução de problemas bibliométricos típicos. Além disso, ao longo de todo o texto, foram assinalados alguns pontos que parecem comuns entre a bibliometria e a Teoria do Caos. Este ensaio, portanto, enseja uma nova questão: a $P O$ poderá contribuir com a ciência da informação, suprindo-a com modelos determinísticos e bayesianos para explicar os fenômenos bibliométricos?}

\section{Palavras-chaves}

bibliometria; Lei de Bradford; Pesquisa operacional; Caos; Ciência da informação; Inferência bayesiana.

\section{Quantitative methods to support Bibliometry: can operational research be an alternative?}

\footnotetext{
Abstract

This work aims to present an alternative way to apply the methods of Operational Research to bibliometric phenomena that appeared in the beginning of the XXth century, and that are polemical until now-a-days. Among several formulations in the bibliometric area, the so called "Bradford's law" is the focus of the present research. Such attempts could be a way to fit bibliometric concepts into a reasonable form, sustaining or discarding descriptions or principles derived from its empirical formulæ. Comparing the journal scattering with some similar phenomena that were studied in Chaos Theory - solved by Operational Research (OP) -, it is possible to find an explanation for the anomalous behavior of Bradford's curves in certain critical conditions. In order to bring some evidence forward to this essay on Bibliometry, two practical cases of OP were adapted in order to solve typical bibliometric problems. Furthermore, there are hints throughout this paper that points out commonalities between Bibliometry and the Chaos Theory. Hence, this essay brought to bear a question on us to think about: could OP contribute to Information Science with deterministic and bayesian models to explain bibliometric phenomena?
}

\section{Keywords}

Bibliometry; Bradford's law; Operational research; Chaos; Information science; Bayesian inference.

\section{INTRO DUÇÃO}

Esteartigo surgiu da extensão de um trabalho de pesquisana disciplina de Pesquisa em C iência da I nformação, no curso dedoutorado em Ciênciadal nformação daU nB (2001), cujo objetivo eraanalisar os diversos métodos de tratamento dos fenômenos bibliométricos quesurgiram no início do século $X X$, até hoje muito polêmicos. A extensão aludidaalinha-se com a propostadeThomas Kuhn para a gênese de ciências pós-modernas, tentando mostrar que é possível produzir conhecimento em bibliometria por analogia com métodos de outros campos do conhecimento aplicados a estes fenômenos.

D euma revisão de literatura expedita de artigos relativamenterecentes que tratam da "lei" deBradford, relativaà dispersão de artigos em diferentes publicações periódicas, surgiu a idéia de investigar os fenômenos bibliométricos por umalinha de analogia aos queforam o embrião da C iência do C aos, de características pósmodernas" como aC iênciadaI nformação.

O risco que acompanha esta anal ogia é amenizado de duas formas. Em primeiro lugar, vem a certeza de quea "lei" de Bradford e suas congêneres na bibliometria "lei" deZipf e "lei" de L otka-, trazem em si o problema fundamental derelacionar essas formulações empíricas a teorias científicas, atormentando muitos pesquisadores: Rudolf C arnap eA natol Rapoport ( apud $\mathrm{O}$ ' $\mathrm{C}_{\text {onnor }}{ }^{1}$ ), $\mathrm{D}$ rott $^{2} \mathrm{eH}$ ubert ${ }^{3}$. Em segundo lugar, vem aoportunidade decontribuir com a integração dos métodos qualitativos e quantitativos, tão decantada pelos estudiosos de metodologiacientífica.

0 germeda concitação a pesquisas futuras neste assunto denaturezamultidisciplinar, repondo em questão às controvérsias bibliométricas, éo quefica de mais expectável. Espera-sequeo atrevimento em lançar o pano de fundo da Teoria do C aos e o material empírico da Pesquisa O peracional ( $\mathrm{PO}$ ), como tentativa de compreender a fenomenologia bibliométrica, não seja de vã contribuição.

\footnotetext{
* Ver noções de ciência pós-moderna em C ardoso, A.N .P. Pósmodernidade einformação: conceitos complementares? Belo H orizonte: Perspectiva-Cl, v.1, n.1, p.63-79, jan./jun. 1996.
} 


\section{Paulo C ésar R odrigues Borges}

\section{ASREV O LU ÇÕESCIENTÍFICAS}

N o final da década de 60 , a ciência se encaminhava para uma crise de especial ização crescente. D ramaticamente, essa tendência para a especial ização foi revertida em virtude do surgimento da $\mathrm{C}$ iência do $\mathrm{C}$ aos. $\mathrm{O}$ s primeiros teóricos do caos eram sensíveis aos padrões, tinham um gosto pelo aleatório, pelo complexo, pelas extremidades recortadas e pelos sal tos súbitos. Pensavam em fazer recuar uma tendência na ciência dita natural - o reduci onismo - , a análise dos sistemas em termos de suas partes constitutivas. A creditam estar à procurado todo $0^{4,5}$.

O s sistemas mais simples criam, como hoje se acredita, os mais difíceis problemas de previsibilidade. $\mathrm{N}$ ão obstante, a ordem surge espontaneamente nesses sistemas - o caos e a ordem, juntos. 0 estudo moderno do caos começou com a assustadora compreensão, na década de 60, de que equações matemáticas muito simples podiam servir de modelo para sistemas tão violentos, sob todos os aspectos, quanto uma queda d'água ${ }^{4,6}$. Pequenas diferenças de insumo podiam transformar-se rapidamenteem esmagadoras diferenças de resultado - um fenômeno que recebeu o nomede "dependência sensível das condições iniciais".

O nde começa o caos, a ciência clássica pára. Este adágio traduz o teor das idéias de Thomas S. Kuhn*, que provocaram tanta hostilidade quanto admiração ao serem publicadas em $1962^{4,7}$. Ele deu uma boa alfinetada na idéia tradicional de que a ciência progride pela acumulação de conhecimento. $\mathrm{N}$ a visão de K uhn, a ciência normal consiste, em grande parte, em operações delimpeza, partindo de onde al guns cientistas pararam, descartando o que outros descobriram, enfim, fazendo avançar as fronteiras da ciência sem replicação deesforços na geração deconhecimento.

M as há as revoluções, segundo K uhn. U manova ciência nasce deuma outra, quechegou aum ponto morto. Com freqüência, uma revolução tem um caráter interdisciplinar - suas descobertas principais vêm, muitas vezes, de pessoas que se aventuraram fora dos limites normais de suas especialidades. 0 s problemas que preocupavam esses teóricos não eram considerados linhas de investigação legítimas. I sso eramuito frustranteparaeles. Todo cientista que se voltou cedo para essas ciências em estado de gestação tem umahistória de desânimo ou de hostilidadeclara para contar. Propostas de suas teses foram rejeitadas eseus artigos não eram publicados. I déias

\footnotetext{
* Em seu famoso ensaio: A E strutura das R evoluções C ientíficas.
}

superficiais podem ser assimiladas; idéias queexigem uma reorganização daimagem quesefaz do mundo provocam hostilidade.

\section{C asos de interesse para a ciência da informação}

Edward L orenz foi o protagonista deuma dessas revoluções. Eletrabalhou em um computador ( valvulado) da décadade60, em seu escritório do M IT. E mbora esta máquina não tivesse a velocidade nem a memória necessárias para uma simulação realista da atmosfera e dos oceanos terrestres, Lorenz conseguiu representar razoavelmente bem o tempo atmosférico.

N o inverno de 1961, querendo examinar mais detidamente uma seqüência, Lorenz tomou um atalho. Em lugar de refazer toda a seqüência, começou pelo meio. Para dar àmáquinasuas condições iniciais, digitou os números diretamentedaimpressão anterior. Q uando retornou, notou que a nova seqüência não se deu como uma repetição exata da anterior. I sto não era esperado. 0 programanão fora modificado. N ão obstante, ao olhar paraa nova impressão, L orenz viu seu tempo divergindo tão rapidamentedo padrão daúltima seqüência, que, em poucosmeses (delaboratório), toda a semelhança desaparecera. Lorenz deduziu que foram os resíduos de cál culo que desprezara até então a causa da mudança. É neste aspecto que um cientista difere de um mero seguidor de fórmulas rígidas demetodologia científica. Lorenz, a partir daí, não desprezaria mais o que era imprevisível no fenômeno complexo daatmosfera, mesmo sendo depequenainfluência.

Para se prever o comportamento de um sistema, atradição científica de $\mathrm{N}$ ewton até L orenz determinavaque deveriam ser desprezadas pequenas influências, tendose à mão um conhecimento sobre as condições iniciais deste sistema euma lei natural que governasse o fenômeno em estudo, mas, quando Lorenz descobriu (por um computador) um padrão em meio ao ambiente caótico das efemérides meteo rológicas, desencadeou um interesse inusitado e crescente em pesquisadores de outras áreas. Por quenão aplicar estametodologiaaos fenômenos bibliométricos?

0 experimento de L orenz recebeu um nome técnico: dependência sensível dascondiçõesiniciais, o que só se dáem um sistema de equações não-lineares, significando isso queexpressavarelações que não eram rigorosamente proporcionais. A s relações lineares são de compreensão fácil etêm solução, o que as torna adequadas para os manuais. 0 s sistemas não-lineares não podem, em geral, ser solucionados $s^{4,13}$. 


\section{Métodos quantitativos de apoio à bibliometria: a pesquisa operacional pode ser uma alternativa?}

A tradição de examinar os sistemas de forma local - de isolar os mecanismos para depois somá-los - estavacomeçando a desmoronar, tanto nas ciências exatas como nas sociais. K uhn estavacerto! N ovas ciências estavam a caminho, e o caos parecia inaugurar esta fase. M as K uhn eramais um filósofo do queum físico ou matemático. Era preciso quecientistas do embrionário estágio dessaciência, por experimentos controlados esistematizados nos corpora dafísica e da matemática, pudessem dar sustentação ao que sevislumbrava em termos de Teoria do $C$ aos. Esses cientistas inauguraram uma forma de conceber toda acomplexidade dos sistemas dinâmicos emesmo de pensar cientificamente* . Físicos, astrônomos e biólogos se convenceram de que tinham de se inteirar das novidades comuns.

U m fato de bastante interesse paraa ciência da informação, que mais pode trazer contribuição para este trabaIho introdutório, éo relacionado às populações deespé cies animais como sistemas dinâmicos, especialmente o cenário maltusiano decrescimento ilimitado depeixes. O s estudos e conclusões do biólogo R obert M . M ay constituem um marco paraaTeoria do $\mathrm{C}$ aos eum ponto de intrigante questionamento para a formulação dos problemas bibliométricos.

Em resumo, $M$ ay coletou dados suficientes de um viveiro de peixes e definiu uma equação que podia prever o desenvolvimento (quedae ascensão) dessa população. Para tornar mais real ista o experimento, $\mathrm{M}$ ay introduziu um parâmetro que quebrava a linearidade do sistema, sendo possível lidar com as seguintes questões: 0 queacontece secolocarmos mil peixes em um tanque com um abastecimento limitado dealimentos? 0 que acontecese juntarmos a isso 50 tubarões quecomem dois peixes por dia? 0 queaconteceseum vírus for introduzido nesseambiente, matando um certo número de peixes a uma certa taxa no tempo, dependendo da densidadepopulacional ? ${ }^{4}$ O s biólogos idealizaram essas perguntas, a fim de poder aplicar as fórmulas rigorosas de model os matemáticos deduzidos para o caso. E por quenão expandir essetipo de perguntas para o campo dabibliometria? $\mathrm{H}$ á mais de sete décadas são feitas as seguintes perguntas: " 0 que acontece se pusermos uma coleção de 1000 livros em uma bibliotecasujeitaa demandas diferenciadas de diferentes tipos deutentes? 0 queacontececom uma coleção em relação ao seu grau de obsoletismo, dadas certas

\footnotetext{
* Peter M. Senge, autor de A 5a Disciplina (1990), propõe o termo metanóia (do gr: meta - além - enous - mente): mudança de mentalidade.
}

injunções: evolução dos meios depublicação eletrônica dessa coleção e contingenciamento orçamentário da unidade deinformação, por exemplo? N a biologia (ena bibliometria, também), uma simplificação útil foi fazer um modelo do mundo em termos deintervalos detempo separados. A s equações diferenciais descrevem processos que se modificam suavemente com o tempo, mas são difíceis deser calculadas. Erapreciso encontrar umafunção linear crescente que constituísse o esquema maltusiano clássico do crescimento da população, não limitado pelo abastecimento de alimentos ou pela contenção moral.

Sem entrar nos pormenores da experiência de M ay, importa saber que el el evantou uma equação para o seu universo de reprodução de peixes, cujos resultados tabulados mostraram-setão intrigantes quanto os formulários deefemérides meteorológicas de Lorenz. 0 algoritmo, facilmente programável em uma pequena calculadora atual, utilizaa população do passo anterior como semente para a próxima interação, verificando-seque a população cresce bastante atéuma determinada interação do início do ciclo de cálculo e depois começa a diminuir. $\mathrm{M}$ ais adiante no ciclo, os valores começam a oscilar em torno de um valor de convergênciae, de repente, afunção seestabiliza.

É válido lembrar que, nos dias do lápis epapel e das calculadoras a manivelas, nunca se pôde ir além de poucas interações ${ }^{4,5,6}$. $\mathrm{N}$ aeradamicroeletrônicaedainformática, iniciada virtual menten a década de 70 , aqueles cál culos queficavam nacasa de dezenas de iterações puderam ser estendidos a até milhões de iterações, revelando o caose padrões nele imersos, sendo este aspecto de muita importância para a bibliometria, em particular, e para a ciência da informação, demodo geral, pelo quesugere do todo, isto é, de como surge uma ciênciapós-moderna.

$\mathrm{N}$ o experimento de $\mathrm{M}$ ay, a introdução do parâmetro de não-linearidade no seu modelo matemático poderia significar fecundidadedos peixes e outros fatores que poderiam af etar a sua reprodução. A perguntaqueesses "novos biólogos" (ecologistas) faziam eraa seguinte: “C omo esses parâmetros diferentes af etavam o destino final de uma população mutável? A resposta óbvia eraque um parâmetro inferior faria com que essa população idealizada terminasse em um nível menor e um parâmetro maior levaria a uma estabilidade maior. I sso se revel ou correto para muitos parâmetros - mas nem paratodos. Q uando parâmetros mais altos foram tentados, o caos começou a surgir. Estranhamente, o fluxo de números começou a secomportar de maneira anômala, o queéum 
aborrecimento para quem está usando uma cal culadora manual. $\mathrm{N}$ ão há convergência nos resultados. D equalquer modo, seapopulação continuava air evir, os ecologistas supunham queela oscilavaem torno dealgum equilíbrio subjacente. 0 equilíbrio era o importante. $\mathrm{N}$ ão Ihes ocorreu que poderia não haver equilíbrio. M as para eles só interessavam soluções estáveis. $N$ inguém queria perder tempo em uma linha de investigação quesetornava irregular, não produzindo nenhuma estabilidade ${ }^{4,5,6}$.

Então, M ay passou atestar o seu modelo matemático em condições críticas (no limite), percebendo que os gráficos que retratavam um comportamento previsível sobre a ascensão ou queda de uma população de peixes, depois de muitas interações, apresentavam um comportamento caótico. N ão obstante, integrando esses gráficos, $\mathrm{M}$ ay notou regiões (franjas) de regularidade em meio à região caótica, queserepetiam em uma recorrência infinita.

0 que fica dessas experiências? A s simulações decompõem a realidade em pedaços, tantos quanto possível, mas sempre menos do que o necessário. U m modelo de computador éapenas um conjunto de regras arbitrárias, escolhidas pelos programadores. E o potencial da surpresa do mundo real? É possível formalizar? Sempreque um bom físico examinaumasimulação, deveperguntar que parte da real idade foi deixada de lado, que surpresa em potencial foi contornada. A simulação em computador pode desenvolver a intuição, evitar gastos em exercícios ou testes reais de campo, aperfeiçoar os cál culos, mas não dá origem a descobertas autênticas. A intuição do cientistaéa chave para as ciências pós-modernas.

\section{PASSAN DO U M ESPAN ADOR N A BIBLIO METRIA}

\section{L ei de Bradford: 0 "rato de laboratório" para a ciência da informação?}

A téaqui, al gumas notas de referência nestetrabal ho tentaram mostrar asimilaridade dos eventos bibliométricos eos de outras ciências tributárias daTeoriado C aos. D aqui em diante, os tópicos mais significativos da "lei" de Bradford serão "inspecionados" (e não analisados) nos seus aspectos gerais e para que o leitor capte a intenção deabrangêlapelo enfoquedo caosepelo método daPO . $\mathrm{N}$ ão vai aqui nenhuma opção de base formal por esta partedabibliometria. $N$ ão há sustentação paraisso, pois nada em termos de cálculo numérico computacional e mesmo desenvolvimentos al gébrico eestatístico puros foram efetuados no trabal ho, afim de sustentar estaescolha, quese deu em termos puramente práticos eapegadosà analogia, pois, como seviu, asimilaridade desiste-
FIGURA 1

\section{G ráfico do regime estacionário de uma população}

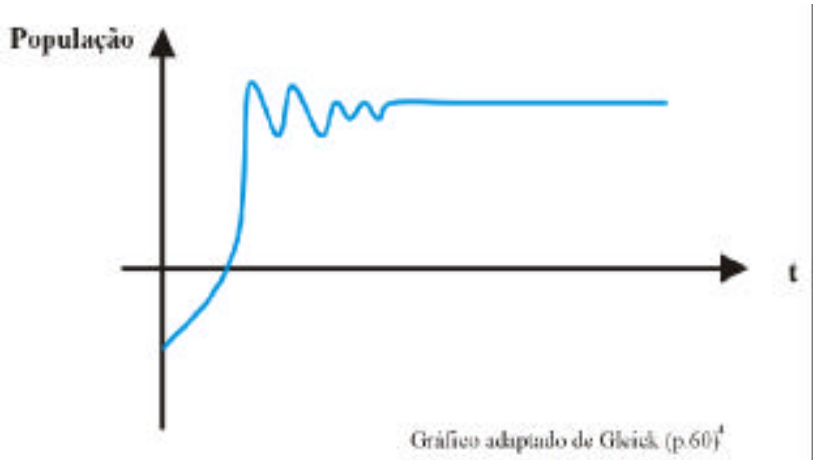

mas não-lineares estudados pelo caos como a dispersão de periódicos parece ser, intuitivamente, um caminho certo atrilhar. Espera-se que esta explicação seja suficiente para afastar a idéia de uma escolha arbitrária (uma predileção subjetiva) pela “lei" de Bradford", se forem considerados como corpus de estudo bibliométrico as congêneres formulações de Lotka e de Zipf. Suplementando esta explicação, além da similaridade fenomenológica citada, há o fato de que al guns problemas de Pesquisa $O$ peracional também podem ser extensíveis à bibliometria, com pequenas adaptações, como se veráa seguir. A baixo, os aspectos mais significativos da "lei" deBradford:

- C riador da "lei": Samuel C. Bradford.

- A no da criação da "lei": 1934.

- Problema que suscitou a "lei": dispersão dos periódicos nas áreas de geofísica aplicada e de lubrificação.

\section{- Modelo matemático:}

\section{EQ U AÇÃO 1}

$$
F(x)=a+b \log x
$$

Em queF $\mathbf{( x )}$ éo número cumulativo de referências contidas no periódico $\mathrm{x}$ mais produtivo ea e e e são coeficientes. H áumafórmula parametrizadada "lei" de Bradford, também muito difundida:

\footnotetext{
*A formulação de Bradford, neste trabalho, não foi considerada como uma lei científica na acepção mais rigorosa do termo, sendo limitada por aspas e iniciada por "I" minúsculo, dando-Ihe o cunho de formulação.
} 
Métodos quantitativos de apoio à bibliometria: a pesquisa operacional pode ser uma alternativa?

EQ U AÇÃ 02

$$
\alpha=10^{\mathrm{s}} \beta=10^{\mathrm{s}+\mathrm{r}} \gamma=\mathbf{1 0}^{\mathrm{s}+2 \mathrm{r}}
$$

Em quer é uma unidade demedidafixa no eixo das abscissas es no eixo das ordenadas. Fazendo $10^{s}=n$, dividindo-se cada equação do sistema de equações da fórmula anterior por $10^{\mathrm{s}} \mathrm{e}$ renomeando-se os termos, a fórmulatransforma-se em uma interessante relação de três membros: 1: $\mathbf{n}: \mathbf{n}^{2}$. Esta relação é muito aplicada no lugar da Equação 2, por admitir a noção de núcleo de periódicos- conjunto de periódicos maisespecificamente dedicados a um certo assunto. A dispersão ficaria mais categorizada, isto é, haveria grupos ou zonas de periódicos especializados contendo o mesmo número de artigos que o núcleo. A quantidade de periódicos dessas zonas obedeceria à relação $1: n: \mathbf{n}^{2}$.

\section{- Representação gráfica: ver figura2.}

\section{- Teor da "lei":}

Em termos simples, a "lei" diz quenão adiantaaumentar excessivamente a quantidade de periódicos, porque a soma dos artigos publicados nos periódicos mais importantes (mais consultados) não vai passar de uma quantidade que seestabilizará ou que tenderáa crescer muito pouco, segundo o comportamento de uma função semilogarítmica.

\section{C ríticasà "lei" de Bradford}

D rott²: desse autor têm-se argumentações mais ligadas aos aspectos teóricos versus os empíricos. Ele começou explicando quea formulação de Bradford foi enunciada com base na regularidade observada na recuperação de informações publicadas sob os aspectos de sua concentração e dispersão. Sua crítica se inicia pelas respostas que deixou de apresentar no próprio campo em que se formou - o empírico -, por exemplo: C omo determinar o tamanho do núcleo deperiódicos? Q ual éo valor ótimo para seatribuir ao coeficiente a daEq. 1, em um certo conjunto de dados? $\mathrm{N}$ o aspecto teórico, questões desta espécie são apresentadas: Q ual éa naturezado processo que causa a distribuição? Q uais as relações entreas variáveis* levantadas que podem explicar o porquêda distri-

\footnotetext{
*Tamanho da amostra, área de especialização do periódico, políticas editoriais,...
}

buição regular deartigos por periódicos? 0 autor alegou quea vulnerabilidade da formulação de Bradford estána falta de sustentação teóricaqueo empirismo dafórmula o btida imprime às variáveis que caracterizam a distribuição, uma vez que nenhuma delas é capaz de contribuir na concepção deum modelo teórico rigoroso para descrever os fenômenos bibliométricos.

C arnap e R apoportapud 0 'C onnor': também argumentaram quea distribuição de vários eventos por faixas constantes de freqüência só permite prever a ocorrência desses eventos, mas não explica as suas causas. A ssinal aram que, apesar de muitas das curvas que descrevem estes tipos dedistribuição seaproximarem muito dehipérboles, nada de teórico fica provado para se afiançar que estas curvas real mentepertencem à classe das hipérboles.

C onsenso crítico: os quatro autores citados concordaram, no entanto, que a "lei" de Bradford constitui um apropriado manancial de utilidade para centros de informação que necessitem de referenciais práticos para o perações de aquisição, armazenamento e distribuição dedocumentos.

H sieh: investigou artigos que tratavam del nteligência A rtificial (I A ) eSistemas Especialistas (SE) no período de1976-1987, utilizando dois meiostecnológicos daépoca: o sistema LISA (Library and I nformation Science A bstracts) e o sistemaW ilsonline. C om basenos resultados bibliométricos obtidos, evidenciou uma produção literária crescente desses assuntos nesse perío do e um significativo deslocamento de contribuições dal A para a ciênciada informação.

Bonitz: contrariou parcialmente $\mathrm{D}$ rott $^{2}, \mathrm{C}$ arnap e R apoport, que, apesar de admitirem uma fragilidade conceitual na "lei" de Bradford, consideravam-na como um método eficiente de tratamento de certas rotinas de uma unidade de informação, especial menteuma bibliotecatradicional. Bonitz criticou a formulação deBradford 


\section{Paulo C ésar R odrigues Borges}

atémesmo para os poucos casos práticos admitidos por seus colegas. D eclarando-se como um estudioso profundo demodelos de distribuição para classificação de eventos probabilísticos, Bonitz refutou ajá pequena margem de aplicabilidade dalei de Bradford, apresentando dois ef eitos ligados às distribuições assemelhadas à de Bradford, expressos por duas variáveis: o efeito da reordenação (ou dareclassificação) e o ef eito do agrupamento. No primeiro efeito, 0 autor ressal tou o fato deser muito importante estabelecer parâmetros significativos para modelar o mais fidedignamente possível a distribuição, sendo necessário muito controlesobre el es. A fiançou que Bradford trabalhou sobre parâmetros muito específicos, aos quais denominou "parâmetros individuais". Bonitz disse que não se pode dizer previamente qual parâmetro éo mais indicado para modelar um fenômeno desse tipo. I sto derruba o poder de predição de fenômenos bibliométricos da lei de Bradford, tirandoIhe o status de tributária de uma teoria científica. 0 outro efeito determinauma variação de curvas em torno da retaideal deBradford. 0 efeito do agrupamento traz em si dois indicadores: a estrutura do acervo documental (jornal, por exemplo) eo perfil do usuário inserido em umaorganização em demandapor documentos.

K havam ${ }^{10}$ : como H sieh ${ }^{8}$, trabal hou no afã de determinar a taxa de contribuição da I A para a bibliometria e, dos estudos quantitativos que efetuou sobreartigos publicados em 1988, concluiu que esta contribuição foi muito mais significativa para as ciências naturais do que para as sociais.

Z ainab et alii ${ }^{11}$ : na mesma linha de $\mathrm{H}$ sieh ${ }^{8} \mathrm{eK}$ havam ${ }^{10}$, concluíram, deum estudo de razoável alcance cronológico (1989-1992) e de extensivo material pesquisado, queexiste umatendência crescente de especialização do pessoal de biblioteconomia nas áreas deSE S SRIS.

\section{C ríticasàscríticas da "lei" de Bradford}

D epois deuma apreciação geral sobrea recente história daformação daTeoria do C aos, percebe-seuma promissorajanela que se abriu paraum sem-número de investigações de ordem teórica no campo da bibliometria. A s dificuldades por quepassou Bradford ao formular suas relações defundo estocástico e, essencial mente, as críticas às suas relações, à meto dologia eàs conclusões que tirou fazem parte de todo um natural processo científico que já deu o que tinha que dar. É nítida uma quasecoincidência entre o teor das críticas dirigidas à "lei" de Bradford eo ceticismo crítico dequeforam al vo os expoentes do caos. Se um aspecto classificatório puder ser em- pregado nestamodesta revisão deliteratura, pode-sedizer queum foco foi sobreabibliografia das ciências puramente exatas equeo outro foi sobreabiblioteconomia. 0 interessante é que tanto $0^{\prime} \mathrm{C}_{\text {onnor }}{ }^{1}$, da área da biblioteconomia, como G leick ${ }^{4}$, Steven $\mathrm{s}^{5}$ e D evaney $^{6}$, da área das exatas, citaram estudos de fenômenos que suscitam o aparente paradoxo da "desordem ordenada", campo fértil para a novata $\mathrm{C}$ iência do $\mathrm{C}$ aos e todas as que delase utilizem para seformar.

$N$ estetópico dedicado à criticadas críticas, optou-sepor el eger para apreciação a obra que pareceu substanciar a crítica mais completaà "lei” de Bradford: a de Bonitz, tanto pelo aspecto epistemológico queencerrava como pelo analítico-formal. 0 próprio título da obra- A false taboo: B radford - é de impacto crítico; um tanto acerbo em relação ao conteúdo do artigo, quetrata de maneira muito racional e sóbria os pontos fracos da "lei" de Bradford edeseus efeitos. G enericamentefalando, Bonitz acreditava na validade da "lei" deBradford somente em situações simples, quando parâmetros específicos são tomados como base para classificação; e, mesmo assim, a maioria dessas situações não está relacionada com as atividades práticas. N esse aspecto, ele criticou até os que defendiam a aplicação da "lei" de Bradford para gerir o dia-a-dia de uma unidade de informação como uma biblioteca.

Entrando em domínios epistemológicos, Bonitz disseque freqüentementeal guns teóricos não põem em questão a forma pela qual uma distribuição é formada. A ssociam um certo fenômeno de seqüência deeventos a formulações matemáticas, esquecendo-se de que, paraum matemático, não há valor de finalidade para suas deduções e descobertas. Paraum matemático, uma curva pode ser aplicada auma fenômeno físico, como o do declínio radioativo de certo mineral, ou mesmo à distribuição de artigos por periódicos, embora haja diferenças gritantes entre as entidades e processos envolvidos. Bonitz também seutilizou de ilustrações que eventos quotidianos sugerem, paratentar explicar osfundamentos de sua crítica, contradizendo-seno aspecto formal quetanto exalta em suas críticas às formulas de Bradford.

A primeira consideração de ordem crítica que se faz às críticas de Bonitz éque, apesar de já haver um vasto repertório de trabalhos sobre o caos, ele não foi capaz de ligar o fenômeno bibliográfico a outros congêneres de outras ciências, ficando muito restrita a sua conclusão, portanto. A o tentar trabalhar com agrupamentos de artigos deperiódicos parao uso deumaorganização, Bonitz notou que a dispersão era muito al ta e que o valor da 
variável a que chamou deefeito do agrupamento do jornal diminuía. 0 efeito, segundo ele, refletiria tanto a estrutura do periódico como o perfil dos usuários da organização em apreço. Bonitz queria saber qual erao conjunto de periódicos que melhor atenderia às necessidades informativas de uma organização. C omo a dispersão deartigos informativos era muito mais al ta em um conjunto de periódicos, o autor deduziu que alinearidade falha pela "lei" de Bradford ( crítica a B onitz: éóbvio!), admitindo duas alternativas: 1a) ou se tem na "lei" de Bradford o caminho único para resolver o problema bibliométrico da dispersão de artigos por periódicos; 2a) ou se deveficar na "companhia segura" da realidade, identificando-se parâmetros que melhor seadaptem aos reais processos dedispersão documentária.

Bonitz não poderiater sido tão infeliz em todo 0 artigo como o foi nestas duas conclusões maniqueístas. A "lei" deBradford, pela finalidade em que se tem insistido há décadas, aplicada à vida vegetativa de uma unidade de informação, é deumatrivialidadeque comprometeatéo senso comum como fonte de conhecimento. $\mathrm{N}$ o entanto, colocá-la como alternativa prejudicada diante da outra alternativa claudicante em termos de possibilidade científica, depois da ascensão do caos, é o mesmo que condenar a bibliometria ao inferno eterno, sem nem Ihe dar a oportunidadedo purgatório. Bonitz não pensou em testar exaustivamente no tempo as interações da simples formulação de Bradford. Em vez disso, optou por recomendar a escolha de parâmetros ajustados à realidade. Q ue parâmetros? Por mais que se escolhessem tais parâmetros, o próprio autor argumentou que um salto brusco na curva de Bradford eraum sinal de anomalia nessa escolha, que deveria receber atenção. É lícito comparar este caso com uma companhia de soldados queentre em forma pela al tura ou pelo peso de seus soldados, não só como analogiailustrativa, mas também para inferir que, se não apenas uma companhia mas um exército decampanha (dezenas de milhares de soldados) entrasse em forma mil hares de vezes por altura emilhares de vezes pelo peso, provavelmenteeclodiria um atrator estranho (a seguir) como evidência mínima deordem em um sem-número de aparentes formações distintas que se dariam apóso comando: "em forma!". Pareceu, também, queBonitz preocupou-se mais com os processos quecom as entidades (objetos e coisas do mundo). I sto écontraproducente pela visão sistêmica. $\mathrm{N}$ a abstração deum modelo conceitual de um sistema, dá-se, no início, mais atenção à definição dos objetos, para, depois, estabelecerem-se as relações (lógicas e ontológicas) quesobreeles podem se aplicar.
A bibliometria pode contribuir para "debutar" a ciência da informação no concerto das ciênciaspós-modernas?

Paraos cientistas do caos, a modelagem gráfica (atratores estranhos) deregiões de estabilidadeem um sistematurbulento era um motor de informação. E com relação à "lei" de Bradford? N ão seria possível transformar o modelo matemático original e suas várias extensões em algoritmos computacionais, de modo a se construir uma teoria mais sólida para a bibliometria? É provável que sim, eum atrator estranho poderá surgir, seas experiências não se ativerem somente a cál culos diretos defórmulas obtidas empiricamente em um espaço amostral reduzido, como foi o de Bradford, em 1934, tentando mostrar como 395 artigos sobre lubrificantes se dispersavam por 164 diferentes periódicos. É provável, também, que os modelos matemáticos para descrever as rela ções empíricas ligadas à dispersão de artigos em diferentes publicações periódicas não sejam realmente consistentes e, por isso, lancem dúvidas até sobre a própria essência dabibliometria, em queàs vezes éposto em xeque o próprio enquadramento dos fenômenos bibliométricos na realidade empírica, observável e mensurável. M as não se pode descartá-los. C omo seviu para a Teoria do $C$ aos, idéias tiradas do esquecimento fizeram avançar as fronteiras de uma nova ciência.

É preciso inaugurar umametanóia bibliométricae, talvez, os ingredientes para isso sejam os seguintes: 1) mentalidade criativa e interdisciplinar do grupo de trabalho (biblioteconomia + matemática + ciência da computação); 2) al goritmos simples eelegantes, queimplementem as diferentes relações construídas para a dispersão de artigos em periódicos, de forma exaustiva; 3) parque tecnológico adequado ( hardware esoftware); eo item mais caro de obter-se: 4) dados.

\section{PESQ UISA OPERACIONAL: UM MÉTODO QUANTITATIVO E ALTERNATIVO DE APOIO À BIBLIO METRIA}

Enquanto não surgir um consenso na definição de uma teoria bibliométrica para as formulações de Bradford e de outros pesquisadores, é conveniente que a estas formulações sejam incorporados os modelos matemáticos de umadisciplinaquesefirmou no meio científico atual: aPesquisa O peracional.

A metodologia aplicada daPO seriauma solução intermediária enova para aumentar o poder deresolução dos problemas bibliométricos, de manter a bibliometria em foco dentro das iniciativas de pesquisa em ciência da 


\section{Paulo C ésar R odrigues Borges}

informação ebiblioteconomia, podendo suscitar muitos trabal hos finais nos cursos de graduação nessas áreas, e, finalmente, a aplicação dessas técnicas, com todo o aporte computacional quetrazem em si, poderiatambém renovar o interesse do público profissional que trabal ha nas unidades de informação modernas.

\section{G eneralidadessobrea Pesquisa 0 peracional}

D efinir a PO como disciplina científica tem sido uma tarefa extremamente difícil, não só por ser uma disciplina nova, mas também pelo seu caráter multidisciplinar. $G$ rande parte das definições simplistas relegam o papel daPO a um ramo da matemática aplicada, preocupada apenas com problemas de "otimização". C omo simples usuária de ferramentas matemáticas aplicadas a problemas da vida real, reduz-se o seu espectro de aplicaçõese prejudica-se a sua real posição de disciplina independente. É também um erro muito comum confundi-lacom afunção gerencial.

H á várias definições, mas uma definição integradora, encontradana disciplina de Teoria da D ecisão do C urso deA Itos Estudos M ilitares daEscolade Comando eEstado-M aior do Exército Brasileiro, éa seguinte:

"PesquisaO peracional éuma pesquisa aplicadaedirigida, dentro das operações de um sistema ou de uma organização, considerados em seu aspecto total. É, outrossim, um método científico detrabalho, queutilizatécnicas einstrumentos científicos, tendo em vista obter o melhor rendimento possível no funcionamento de uma organização ou o melhor desempenho possível de um sistema em estudo. Baseia-se em análises quantitativas para auxiliar o processo de decisão."

0 berço da PO, no Brasil, remonta à década de 50 , em que professores das áreas de matemática, estatística e engenharia do I M E (I nstituto M ilitar de EngenhariaRJ), ITA (Instituto Tecnológico da A eronáutica-SP), U SP e daU FRJ já se entusiasmavam com o potencial desse campo de pesquisa. A pesar das dificuldadestípicas da introdução de novas técnicas e de mudanças de padrões funcionais em uma organização, os resultados da PO têm motivado muitos indivíduos e grupos, acostumados com a rápida absorção de novas tecnologias que dão certo, o que, inevitavelmente, criará um ambiente favorável para a sua disseminação nos meios governamental, comercial e industrial, visto que, no acadêmico, isto jásedeu.
O objetivo geral daPO éo de descobrir regularidadeem algum fenômeno eligar essa regularidade com outros conhecimentos, de tal forma que o fenômeno possa ser modificado ou controlado. N ão são do escopo daPO atividades de limitar técnicas e instrumentos para a solução de problemas como um todo. Seum problema pode ser resolvido somentepor princípios e técnicas deengenharia, então éum problemadeengenharia, enão dePO .

A PO, a cada dia que passa, tem sido mais aplicada na área das ciências sociais, especialmente na administração, promovendo um desenlace com o tradicional método quantitativo, monopólio das ciências exatas pela visão reducionista do positivismo. 0 enfoque qualitativo foi trazido, por conseguinte, pelos administradores de empresa, incomodados com o excesso derigor matemático dos métodos dePO e, muitas vezes, frustrados pela poucaflexibilidadedos modelos, querespondiam somentea perguntas padronizadas. 0 enfoquequalitativo da $P O$ éo reconhecimento de que o tratamento quantitativo dos problemas forneceuma estrutura de raciocínio e análise que permite descobrir qual éa informação necessária para se desencadear afase qual itativa de resolver 0 problema mais amplo. É ametanóia naPO .

Em que pese a profusão de variáveis para resolver problemas nesses novos campos de aplicação da PO , uma limitação ao seu método continuaa ser o derestringir o número de variáveis parase poder construir um modelo quefuncione. A evolução para uma aplicação qualitativanaPO não pôde absorver integralmente a aberturaa um número excessivo de variáveis para representar 0 mundo real. Foi uma trocacom limites, mas que, se não resolve todos os problemas desses novos campos, pelo menos acende um farol no fim de um túnel denebulosos e confusos contextos, que havia antes dessa integração daPO àsciências sociais.

A s técnicas de PO mais empregadas estão organizadas nas seguintes categorias: 1a) Programação Linear: envolvendo problemas de programação linear, programação linear inteira, problemas de transporte, problemas detransbordo, problemas de designação e problemas de alocação de recursos; 2a) A nálise de Redes: envolvendo problemas de árvore geradora mínima, caminho mais curto efluxo máximo; 3a) Teoriados Estoques; 4ㄹ) Teoria das F ilas; 5a) Simulação deSistemas; 6ạ) Teoria dos Jogos; 7ạ) Programação D inâmica: trata de problemas ligados à Teoria daD ecisão e daTeoria daU tilidade. Pelo tom que seu deu a estetrabalho, só serão utilizadas ala e a 7 a técnicas. É por isso que elas serão descritas a seguir. 
A programação linear cuida dos problemas de determinação de valores máximos e mínimos de funções, sem contudo tratar de variáveis que produzam ou armazenem valores negativos. $\mathrm{N}$ ormal mente, 0 sistema de equações é indeterminado, isto é, hámais variáveis que equações, acarretando um sem-número de soluções para este sistema, que expressa as restrições tecnológicas ou econômicas naliberdade de ação de uma organização. A inda dentro da programação linear, uma classe de problemas de amplo espectro de aplicação é a de transporte. U m problemadetransportese resumeem determinar o carregamento de uma rede detransporte queliga várias fontes a vários destinos, de forma que o custo total do transporte na redeseja mínimo.

O s problemas deprogramação dinâmica estão calcados na disciplina de Probabilidade eEstatística, bem como em um rebento desta: al nferência B ayesiana da I A . 0 problema mais essencial desses campos é o de tentar "medir" a incerteza que afeta um sistema, em seus mais variados aspectos. $\mathrm{N}$ esse ponto ébom distinguir al gumas noções que diferenciam a análise bayesiana dos métodos probabilísticos convencionais. ${ }^{12,13}$

O s problemas de decisão (TeoriadaD ecisão) exploram quatro tipos de contexto, na ordem crescente de indeterminação: a certeza, o risco, a incerteza eo conflito. A stécnicas (V. probleman-2, a seguir) quepodem ser aplicadas a esses contextos são as seguintes: para problemas decerteza, a programação linear; para os de risco, a Teoria da Probabilidade; para os de incerteza, a análise bayesiana; e para os de conflito, a TeoriadosJ ogos. A árvore de decisão constitui aferramenta básicadesolução desses problemas. É uma estrutura ramificada ou um diagrama de probabilidades, em que a cada ramo da árvoreéassociada uma probabilidade de ocorrência de um evento; a cada nó de probabilidade (simbolizado por um círculo) éassociado o valor da esperança matemática acumulada para aquelenó; a cada nó de decisão ( simbolizado por um quadrado), éassociado um valor referente ao somatório mais favorável das esperanças matemáticas dos ramos tributários. 0 caminho da árvore (detrás para a frente) que maximiza a vantagem ou minimizaa desvantagem constitui alinha de ação a ser adotada. Pode ser necessário aplicar um método estatístico convencional ou mesmo o Teorema de Bayes em algum ramo da árvore, nesses tipos de problema.

A chamadaI nferência B ayesiana, muito explorada hoje em dia pelal A, vem de muito tempo atrás - do abadee matemático inglês Thomas Bayes (1702-1761). Bayes tentou determinar a probabilidade das causas por inter- médio dos efeitos observados. G rosso modo, o tamanho e conhecimento quesetem da amostraéo fator que determinaráa escolha deuma distribuição daProbabilidadee Estatística clássica (funções de verossimilhança) ou do Teorema de Bayes (distribuição a priori) . I nfelizmente, muitas vezes é difícil coletar etratar dados parauma experiência, nada melhor queutilizar as funções deverossimilhançaetrabalhar com estimadores clássicos da Probabilidadee Estatística. D o contrário, se os únicos dados disponíveis são de uma amostra pequena e pouco confiável (mais subjetiva), então é útil trabalhar com uma distribuição a priori. Em al guns problemas deciências sociais, a estimativa com base em grandes amostras em quese podeconfiar éimpossível ou proibitivamente dispendiosa. Então, a análise bayesiana proporciona um esquema para a to mada de decisões racionais ${ }^{13}$. 0 "veIho" Teorema de Bayes, na atual conjuntura de pósmodernidade, acabou por produzir fecundos rebentosem pesquisas naárea del $A$, voltadas à aval iação do conhecimento impreciso (incerteza). D aí veio a Teoria daEvidência de A. P. Dempster (1968), posteriormente reformulada por G. Shafer (1973), cujos objetivos confluem paraaformalização de uma "metodologia de decisão", baseada em uma função de crença, em uma função deperda eno princípio da maximização da utilidadeesperada, em um contexto de ignorância parcial, sendo vasto o campo de aplicações, por exemplo: 1) preferências eleitorais; 2) indexação automática de documentos; 3) representação daincerteza de regras, solução deconflitos de regras, etc. ${ }^{12}$

\section{R esolução de problemasbibliométricos por programa- ção linear e por árvore de decisão}

Paraaelaboração deum modelo desolução paraum problema dePO , os passos são os seguintes: 1 ํ) formulação do problema; 2으) definição das variáveis de decisão; 3으) estabelecimento da função-objetivo; 4ㅇ) formulação das equações de restrição; 5ㅇ) formulação do modelo. N este tópico, as fases acima serão vistas em situações reais da bibliometria, adaptadas de problemas dePO naárea de administração de empresas.

\section{Problema no 1 (programação linear):}

O bibliotecário-chefe de uma grande unidade deinformação estátentando "otimizar" as diversas aquisições de periódicos quefaz a quatro tipos de usuários: universitários, industriais/ comerciantes, estudantes de 20 grau e estudantes de 10 grau. 0 s recursos de que dispõe para isso permitiriam a aquisição de 50.000 exemplares de quatro categorias correspondentes àqueles públicos-al- 


\section{Paulo C ésar R odrigues Borges}

vos. A s probabilidades desucesso ede riscos com os empréstimos correspondentes a cada categoriaforam tabuladas como mostraa tabela 1. H á um mínimo de restrições que devem ser seguidas:

1a) a aquisição de periódicos para estudantes do $1^{\circ}$ e e $2^{\circ}$ graus não deve ultrapassar $40 \%$ do val or total de exemplares a serem adquiridos;

2a) as aquisições para estudantes do 1 음 grau não podem exceder $20 \%$ do total dos exemplares a serem adquiridos para estudantes do 10 e 20 graus;

3a) o total das aquisições para industriais/ comerciantes não deveexceder a 10.000 exemplares;

4a) a probabilidade de risco não deve exceder $0,8 \%$ da aquisição total.

Pede-se determinar, por programação linear, o total de exemplares a serem adquiridos em cadatipo de público, demodo a maximizar o sucesso naoperação deempréstimo de periódicos dessagrandeunidade deinformação.

\section{Solução:}

\section{a. D efiniçãa dasvariáveis de decisão}

- $\quad \mathrm{X}_{1}=$ aquisição para universitários

- $\quad X_{2}=$ aquisição para industriais/comerciantes

- $\quad X_{3}=$ aquisição para estudantes do $2^{\circ}$ grau

- $\mathrm{X}_{4}=$ aquisição para estudantes do $2^{\circ} \mathrm{g}$ grau

\section{b. Estabelecimento da função- objetivo}

Com se deseja que o sucesso na aquisição seja máximo, deve-se considerar os públicos de maior emenor risco para a aquisição. A ssim, se existe $0,2 \%$ derisco na aquisição de periódicos para os universitários, há $99,8 \%$ de possibilidadedesucesso. Logo, para a primeiracategoria de aquisição, tem-se $(0,998 \times 0,09-0,002) X_{1}=$ $0,08782 X_{1}$

D eforma análoga, para as outras categorias, tem-se:

$(0,995 \times 0,10-0,005) X_{2}=0,0945 X_{2}$

$(0,990 \times 0,13-0,010) X_{3}=0,1187 X_{3}$

$(0,980 \times 0,14-0,020) X_{4}=0,1172 X_{4}$
TABELA 1

Probabilidades de sucesso e risco no empréstimo de periódicos.

\begin{tabular}{lcc}
\hline U suário & $\begin{array}{c}\text { Probabilidade } \\
\text { de sucesso }\end{array}$ & $\begin{array}{c}\text { Probabilidade } \\
\text { derisco }\end{array}$ \\
\hline U niversitário & $9 \%$ & $0,2 \%$ \\
Industrial/comerciante & $10 \%$ & $0,5 \%$ \\
Estudante do $2^{\circ}$ grau & $13 \%$ & $1,0 \%$ \\
Estudante do $1^{\circ}$ grau & $14 \%$ & $2,0 \%$ \\
\hline
\end{tabular}

Então, afunção-objetivo será a seguinte: $M$ aximizar $\mathrm{z}=$ $0,08782 X_{1}+0,0945 X_{2}+0,1187 X_{3}+0,1172 X_{4}$

\section{c. Formulação dasinequações de restrição}

- A s aquisições para os estudantes do 10 e do 20 graus não devem ultrapassar $40 \%$ do total : $X_{3}+X_{4} \leq 0,4$ ( $X_{1}$ $+X_{2}+X_{3}+X_{4}$ ), ou seja: - $0,4 X_{1}-0,4 X_{2}+0,6 X_{3}+0,6 X_{4}$ $\leq 0$

- A s aquisições para os estudantes de 10 grau não devem exceder $20 \%$ do total deaquisições paraestudantes do 10 e 20 graus: $X_{4} \leq 0,2\left(X_{3}+X_{4}\right)$, ou seja: $-0,2 X_{3}+$ $0,8 \mathrm{X}_{4} \leq 0$

- 0 total de aquisições para os estudantes do 10 grau não deve exceder a 10.000: $X_{2} \leq 10.000$

- A s aquisições para os universitários não devem ser menores que 20.000: $X_{1} \geq 20.000$

- 0 risco não deveultrapassar $0,8 \%$ das aquisições totais:

$0,002 X_{1}+0,005 X_{2}+0,01 X_{3}+0,02 X_{4} \leq 0,008\left(X_{1}+\right.$ $\left.X_{2}+X_{3}+X_{4}\right)$

F azendo as operações esimplificações necessárias, vem: $-0,6 X_{1}-0,3 X_{2}+0,2 X_{3}+1,2 X_{4} \leq 0$

- A quantidade total de aquisições é de 50.000, donde vem que $X_{1}+X_{2}+X_{3}+X_{4} \leq 50.000$

Pelo princípio da não-negatividade da programação linear, tem-se que $\left\{X_{1}, X_{2}, X_{3}, X_{4}\right\} \geq 0$

\section{d. Formulação do modelo}

Encontrar valores para $\left\{X_{1}, X_{2}, X_{3}, X_{4}\right\}$, de forma a maximizar a função-objetivo já estabelecida, com as restrições levantadas na letrac. C omo o número de equações é maior que o número de incógnitas (variáveis) , 0 
sistema ésuperabundante, admitindo infinitas soluções. A maneira dese resolver estetipo de problemanão será aqui explicitada efoge ao objetivo deste trabal ho ( não faz parte dos métodos normais de solução daálgebralinear), valendo dizer quefoi empregado um programa de ajustamento complexo (transformação estatística), desenvolvido na linguagem de programação F ortran 77. $D$ aí, o resultado obtido em números de exemplares foi o seguinte:

$X_{1}=20.000 ; X_{2}=9.999 ; X_{3}=20.000 ; X_{4}=0$

\section{Problema no 2 (programação dinâmica - árvore de de-} cisão):

N este problema não se fará uma adaptação específicaa um problema bibliográfico. Eleserá expresso em uma forma o mais genérica possível, detal sorteque possa ser adaptado a rotinas administrativas de uma organização para a aquisição de bens ou para o oferecimento deserviços o mais adequados evantajosos possíveis.

Enunciado: suponha que uma organização válançar um produto ou oferecer um serviço para um universo de usuários (cativos, potenciais etc.) . A diretoria da organização reúne-se elevanta três linhas de ação:

a) desistir do lançamento do produto ou da prestação do serviço;

b) Iançar imediatamente o produto ou prestar imediatamente o serviço;

c) efetuar uma pesquisa demercado (produto) ou distribuir um questionário (serviço) para optar por A ou por $B$, dependendo do resultado.

O s resultados das pesquisas podem ser "pouco favorável", "regular" ou "muito favorável", com as probabilidades de $50 \%, 25 \%$ e $25 \%$, respectivamente. A probabilidade de o produto ou o serviço fazerem sucesso sem a pesquisa é de $30 \%$ (note queas probabilidades jáforam fornecidas, não sendo necessário calculá-las).

O departamento de planejamento da organização avaliou que o sucesso propiciará um retorno de $3.000 \mathrm{U} \mathrm{M}$ (unidades monetárias) eo insucesso, um prejuízo de 250 U M. Sabe-seque o custo da pesquisa seráde 50 U M.

Conhecem-se, ainda, as probabilidades de o produto ou deo serviço terem sucesso, dado quea pesquisa apresentou os seguintes resultados:

Ci. Inf., Brasília, v. 31, n. 3, p. 5-17, set./dez. 2002
FIGURA 3

Á rvore de decisão do problema no 2

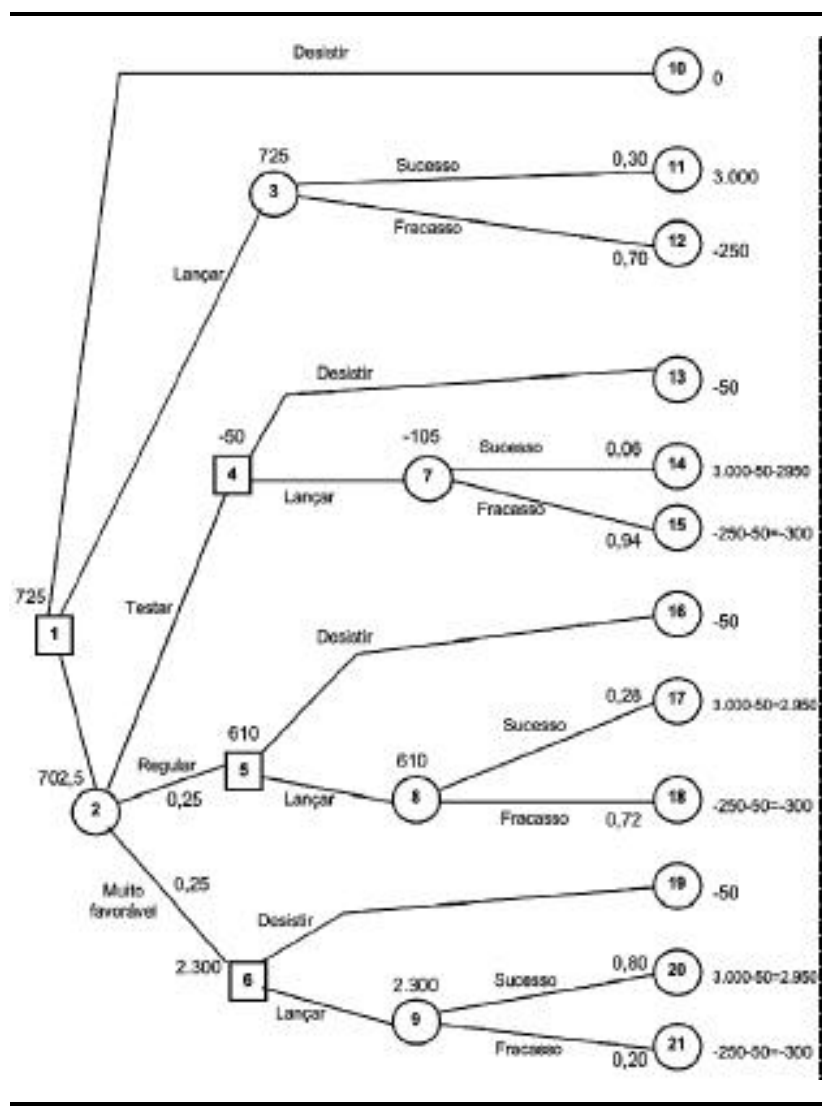

- "pouco favorável" = 6\%

- "regular" $=28 \%$

- "muito favorável" = $80 \%$

Pede-se desenhar aárvore de decisão do problema edeterminar a melhor linha de ação para a organização, baseando-se no critério do valor matemático esperado.

A Eq. 3 éa fórmula para o cálculo do valor matemático esperado.

O coeficientec é éo valor matemático esperado do evento $\mathrm{P}\left(\mathrm{c}_{\mathrm{i}}\right)$ éa probabilidade associada àocorrência.

Solução:

- D a árvore de decisão da figura 3, extraem-se os seguintes valores:

$\mathrm{VME}_{3}=3.000 \times 0,30-250 \times 0,70=725$

$\mathrm{VME}_{7}=2.950 \times 0,06-300 \times 0,94=-105$ 


\section{Paulo C ésar R odrigues Borges}

$\mathrm{VME}_{8}=2.950 \times 0,28-300 \times 0,94=610$

$\mathrm{VME}_{9}=2.950 \times 0,80-300 \times 0,20=2.300$

$\mathrm{VME}_{2}=-50 \times 0,50+610 \times 0,25+2.300 \times 0,25=702,5$

- D ecisão: como VME3 > VM E2, amelhor alternativa élançar o produto ou oferecer o serviço, sem realizar a pesquisa.

$$
V M E_{i}=\sum_{i=1}^{\sum c_{i}} P\left(c_{i}\right)
$$

\section{CONCLUSÃO}

É bom lembrar que na recente história das disciplinas que compõem o corpus da ciência da informação, a eventual contribuição de certos "forasteiros" das ciências ditas "duras" ( hard sciences) ou físicas foi muito auspiciosa. 0 austríaco Eugênio (Eugen) Wüster, quedesenvolveu a Teoria G eral daTerminologia, foi um exemplo, pois era um engenheiro. Benoit $M$ andelbrot, matemático e um dos "pais" daTeoria do C aos, interessou-semuito pela enigmática "lei" de G eorge Kingsley Zipf* , filólogo de $\mathrm{H}$ arvard. Portanto, mais uma vez, fica o conviteparaque mais "forasteiros" seinteressem em destrinçar essas formulações empíricas queforam orladas desdeo início do século por pesquisadores da biblioteconomia, dalingüística, enfim, das soft sciences, ainda aguardando o toque final da parceriainterdisciplinar com ashard sciences, para erigir uma disciplina ou mesmo um campo científico, mandamento capital dapós-modernidade científica.

Com a recentehistória da bibliometria, pode-se dizer que existeumalinha de similaridade com o que ocorreu com o caos. M uitas das iniciativas de pesquisadores do início do século, quededuziram expressões bibliométricas empíricas, foram deixadas de lado, mas podem ser $0 \mathrm{em}$ brião de uma nova disciplina, se ressuscitadas com novos recursos, principalmente os que a ciência da informação vem carreando para o seu corpus, enriquecido por métodos e instrumentos de outras ciências.

* Esta lei trata da freqüência de ocorrência de palavras em um texto.
U ma conclusão éumaasserção. $\mathrm{N}$ o entanto, com laivos de intrigar o leitor, prefere-se "questionar" nesteitem em vez deconcluir. A squestões queseseguem trazem em si o espírito afirmativo das respostas ( seu conjunto $=$ conclusão), pelo objetivo não formalmenteexpresso destetrabalho dealiar o método seguido pelos criadores do caos ao caminho incerto de a bibliometria descrever os fenômenos deseu interesse. R esponder a estas perguntas com incursões investigativas formais é justificar um constructo matemático para abibliometria, norteando a sua análise por métodos validados cientificamente. Sendo assim, eis as perguntas:

- Poderiao aprofundamento da pesquisabibliométrica trazer àtona uma gama de resultados que a alçasse como disciplinacientífica?

- Isto seriaum cartão de entradada ciência da informação para o universo das ciências pós-modernas?, idealizado por Thomas Kuhn?

- O quadro da não-linearidade é extensível aosfenômenos de dispersão de artigos e outros de interesse da bibliometria?

- Como encarar a não-linearidadebibliométrica, se ela ocorrer? Procurar por um ponto em comum com um fenômeno que suscite um comportamento não-linear de um sistema de outro campo científico é um caminho a ser seguido?

C rê-sequeaformalidadeque for impressaàrespostadessas questões poderá amenizar as críticas dos autores que, com razão, não enxergam rigor científico nas proposições e model os matemáticos de Bradford. ParaK uhn, al guns cientistas ( sociais ou das exatas) se desorientam quando aplicam seus métodos tradicionais de pesquisa. Eis o momento paraqueos cientistas dainformação aproveitem os insumos metodológicos de outras ciências. A matemáticaaplicadaeo cálculo numérico* , como principais tributárias daPO , podem levar as críticas ao fim ou a planos mais objetivos de orientação. A profissão de cientista tem de encarar as anomalias em seus resultados, não tentando mais conduzi-los à "normalidade" por métodos de aproximações, isto é, desprezando resíduos não-lineares. A Teoria do $C$ aos e os métodos da PO para a solução de problemas caóticos são, por enquanto, os únicos meios disponíveis paralidar com essas "anomalias".

* D isciplina da ciência da computação que se preocupa com métodos numéricos para resolver, principalmente, problemas matemáticos de divergência na solução de sistemas de equações. 


\section{Métodos quantitativos de apoio à bibliometria: a pesquisa operacional pode ser uma alternativa?}

"Lei" de Bradford + técnicas dePO + Teoria do C aos! Talvez repouseaí o pacote de surpresas que daráum novo sentido à ciência da informação, começando por resolver os problemas bibliométricos, ou, melhor queresolvêlos, criar novos problemas nessa estacionária disciplina, que guardatanto potencial teórico-prático.

A rtigo aceito para publicação em 03-12-2002

\section{REFERÊNCIAS}

1. O 'CON N O R, D aniel O .; VO O S, H enry. Empirical laws, theory construction and bibliometrics. N ova Jérsei : Escola de Biblioteconomia e de Estudos de I nformação da U niversidade de Rutgers U niversity, 1981. p. 9-19.

2. DROTT, M. C arls. Bradford's law: theory, empiricism and the gaps between. Filadélfia : Escola de Biblioteconomia e de Ciência da Informação da U niversidade de D rexel, 1981. p. 41-51.

3. H U BERT, John J. G eneral bibliometric models. O ntário: U niversidade de Guelph, 1981. p. 65-79.

4. GLEICK, James. CAO S: a criação de uma nova ciência. Rio de Janeiro : C ampus, 1990. $310 \mathrm{p}$.

5. STEVEN S, R. T. F ractal: programming in C . C alifornia : M\&T Books, 1989. $583 p$
6. DEVANEY, R. L. C haos, fractals, and dynamics: computer experiments in mathematics. C alifornia : A ddisson-Wesley, 1990. $181 \mathrm{p}$.

7. ATAÍDE, M.E.M. O lado perverso da globalização na sociedade da informação. C iência da Informação, Brasília, v. 26, n. 3, p. 268270, set. 1997.

8. H SIEH , C ynthia C. Survey of artificial intelligence and expert systems in library and information science literature. I nformation Technology and Libraries, C alifórnia, v. 8, n .2, p. 209-214, Jun. 1989.

9. BO N ITZ, M anfred. A false taboo: Bradford. International F orum on Information and D ocumentation, M oscou, v. 16, n. 2, p. 15-17, A pr. 1991.

10. KHAVAM, Y ves. L' apport de la bibliometrie aux recherches interdisciplinaires. Le cas de l' intelligence artificielle. D ocumentalisteSciences de L' I nformation, Paris, v. 29, n. 3, p. 129135, mai./juin. 1992.

11. ZA IN A B, A wang N gah; SI LVA, Sharon M anel de. Expert systems in library and information services: publication trends, authorship patterns and expressiveness of published titles. J ournal of I nformation Science, Brighton, v. 24, n. 5, p. 313-336, 1998.

12. SI LVA, Wagner Teixeira. Algoritmos para raciocínio evidencial usando funções de crença. 1991. 214 f. Tese (D outorado) - PU C -RJ. Rio de Janeiro, 1991.

13. WO N N A C O TT, Thomas H .; WO N N A C O TT, Robert J. I ntrodução à estatística. São Paulo : LTC , 1980. 589 p. 